\title{
Recruitment and Post-recruitment Dynamics of the Barnacle Semibalanus balanoides on a Wave-Exposed Headland in Atlantic Canada
}

\author{
Ricardo A. Scrosati ${ }^{\star}$ and Janelle K. Holt \\ Department of Biology, St. Francis Xavier University, Antigonish, NS, Canada \\ Keywords: barnacle, Cirripedia, Crustacea, intertidal, recruitment, Semibalanus balanoides
}

\section{INTRODUCTION}

The intertidal barnacle Semibalanus balanoides (Crustacea, Cirripedia) is a common organism on

OPEN ACCESS

Edited by:

Francesca Porri,

South African Institute for Aquatic Biodiversity, South Africa

Reviewed by:

Paul South

Cawthron Institute, New Zealand

Eleonora Puccinelli,

Université de Bretagne

Occidentale, France

*Correspondence:

Ricardo A. Scrosati

rscrosat@stfx.ca

Specialty section:

This article was submitted to

Marine Biology,

a section of the journal

Frontiers in Marine Science

Received: 21 October 2021 Accepted: 17 November 2021 Published: 08 December 2021

Citation:

Scrosati RA and Holt JK (2021) Recruitment and Post-recruitment

Dynamics of the Barnacle

Semibalanus balanoides on a Wave-Exposed Headland in Atlantic Canada. Front. Mar. Sci. 8:799514. doi: 10.3389/fmars.2021.799514
North Atlantic rocky shores (Hutchins, 1947; Bousfield, 1954; Crisp, 1964; Jenkins et al., 2000; Flight et al., 2012; Crickenberger and Wethey, 2018). Adults are sessile and reproduce through pelagic larvae. Due to its wide niche breadth, its various ecological roles (filter-feeder, competitor, facilitator, and prey), and its utility as an ecological indicator, it has often been used as a model species to advance ecological theory (Connell, 1961; Menge and Sutherland, 1976; Bertness et al., 1999; Belt et al., 2009; Burrows et al., 2010; Crickenberger and Wethey, 2018; Scrosati and Freeman, 2019; Scrosati, 2021). Recruitment is an aspect of its life cycle that has particularly been investigated, given its relevance for population replenishment and persistence. For barnacles, recruitment refers to the appearance of new organisms on the substrate as a result of the metamorphosis of settled larvae. Settlement refers to the permanent attachment that the pelagic larvae establish on a substrate (Jenkins et al., 2000; Blythe and Pineda, 2009).

The magnitude of annual recruitment is often estimated as recruit density measured at a point in time selected by the researcher. When the timing of the recruitment season (the period during which recruits appear on the shore) can be anticipated with some confidence, recruit density is typically measured as close as possible to the end of this period to quantify annual recruitment. This approach, however, may miss early recruits that may die and be removed from the substrate by natural causes before recruit density is measured. The resulting underestimation of annual recruitment may thus limit our understanding of recruit ecology (Minchinton and Scheibling, 1993; Shanks et al., 2014). On the other hand, unpredictable natural variation may add additional recruits after recruit density is measured if the recruitment season is longer than anticipated. Thus, recruitment dynamics are best studied through frequent field surveys spanning the recruitment season and dates beyond its suspected end. Conducting frequent surveys during the recruitment season also matters because the drivers of recruit performance (e.g., pelagic food supply, environmental stressors, and benthic predators) often vary in intensity during that period (Menge, 2000).

On the open Atlantic coast of Nova Scotia (Canada), the recruitment of Semibalanus balanoides typically takes place in May and June (Ellrich et al., 2016a). This article discusses the recruitment and post-recruitment dynamics of $S$. balanoides from this coast using data on recruit appearance, mortality, density, and size collected frequently between May and October 2019. We discuss the salient temporal patterns in a context related mainly to $S$. balanoides recruitment. 


\section{MATERIALS AND METHODS}

We did this study at Western Head, a prominent rocky headland located on the Atlantic coast of Nova Scotia $\left(43.9896^{\circ} \mathrm{N}\right.$, $64.6607^{\circ} \mathrm{W}$; Figure 1A). We took all measurements in intertidal bedrock areas that directly face the open ocean, so these are waveexposed habitats (Figure 1B). Maximum water velocity measured in nearby wave-exposed intertidal habitats can reach $12 \mathrm{~m} \mathrm{~s}^{-1}$ (Hunt and Scheibling, 2001). To establish our sampling units, we first determined the elevation (in $\mathrm{m}$ above chart datum, or lowest normal tide) of the upper distribution boundary of the sessile perennial species that occurred highest on the shore (coincidentally, Semibalanus balanoides) on rocky surfaces excluding tide pools and crevices. This vertical distance was $2.2 \mathrm{~m}$, which is similar to the maximum tidal amplitude for this location (2.3 m, Tide and Current Predictor, 2021). We then divided this vertical distance in three and measured all recruit variables (named below) just above the lower boundary of the upper third of this vertical range. Therefore, our barnacle data were measured at an elevation of $1.5 \mathrm{~m}$. This high-to-middle elevation was selected because barnacles are abundant there and also to make our data comparable with recent barnacle surveys done at that elevation at other wave-exposed locations along the Atlantic coast of Nova Scotia (Scrosati and Ellrich, 2018, 2019).

To measure barnacle recruitment unaffected by other sessile species, in late April 2019 (shortly before the recruitment season) we cleared eight patches of rocky substrate spaced at random along the coastline at the targeted elevation. From each patch, we removed all sessile organisms with a chisel and a metallic scrubber. At the center of each patch, we delimited a square area $(10 \mathrm{~cm} \times 10 \mathrm{~cm})$ permanently by marking two vertices on the substrate to ensure accurate relocation of such clearings across sampling dates. On the Nova Scotia coast, natural rock clearings provide more realistic measures of barnacle recruitment than plates covered with 3M Safety-Walk tape, which are used on other coasts (Scrosati and Ellrich, 2018). We took photographs of the square clearings during low tides (framing the clearings with a $100-\mathrm{cm}^{2}$ quadrat) on 2 May, 9 May, 10 May, 17 May, 23 May, 28 May, 1 June, 9 June, 13 June, 24 June, 3 July, 22 July, 20 August, 2 September, and 26 October. The surveys were more frequent during May and June to discern the dynamics of recruitment, although surveys could not then be done more often because of tide dynamics and wave action.

We analyzed the photographs with ImageJ to determine the appearance, size, and survival of each recruit throughout time. These measurements were possible because barnacles remain permanently attached to the substrate after larval settlement and metamorphosis (Blythe and Pineda, 2009). The appearance of a recruit was recorded for a given sampling date when that recruit was absent in the previous sampling date. The size of a recruit was measured as the basal diameter of its shell (Bertness et al., 1991). The mortality of a recruit was recorded for a given sampling date when only the shell plates of a previously live individual were observed on that date ("empty" shell).

Because of natural topographic heterogeneity (Helmuth et al., 2006; Harley, 2008; Mislan et al., 2011; Sejr et al., 2021), differences among the clearings relevant to this study became apparent during the surveys. Some clearings seemed to receive more wave splash than others. Thus, for most dates in May (when wave action was often intense), a visually reflective film of water remained over four of the eight clearings during the low tide; this water layer could not be removed to take pictures due to wave action. In addition, ephemeral green algae appeared on those four clearings during May, likely favored by those conditions. These unexpected developments prevented us from accurately identifying the barnacle recruits from those four clearings for most of May. Therefore, we are reporting results for the four clearings that were possible to monitor in detail throughout the entire study period. These clearings are representative of Western Head because they spanned the studied coastline along the targeted elevation.

In this article, the barnacles that appeared in May and June and were monitored until October are always referred to as recruits even though many of them reached adult size in October. This approach facilitates the description of temporal patterns by making clear that only the organisms recruited in May and June 2019 were monitored. The data collected for this article are freely available from the figshare online repository (Scrosati and Holt, 2021).

\section{RESULTS}

\section{Barnacle Recruitment}

The first recruits appeared at some point between 2 and 9 May (no recruits were seen on 2 May) and the last recruits appeared between 13 and 24 June (no new recruits were seen after 24 June). During this period, the daily rate of barnacle recruitment varied significantly over time (repeated-measures ANOVA, $F=3.43, P$ $=0.017$; Figure 2A). By 17 May, $74 \%$ of the recruits identified in this study had already appeared on the substrate, while $90 \%$ of all identified recruits were on the substrate by 28 May. Therefore, recruitment in June was low. The highest value of recruitment rate obtained for a single quadrat $\left(11\right.$ recruits $\mathrm{dm}^{-2}$ day ${ }^{-1}$ ) was recorded on 10 May. A visual example of the temporal changes in recruitment is offered in Figure 1C.

\section{Recruit Mortality}

No recruit deaths were recorded during the recruitment season (May and June) or in early July. Dead recruits were only found between 22 July and the end of the study on 26 October. During this period, the daily mortality rate of recruits did not vary significantly (repeated-measures ANOVA, $F=0.95, P=0.456$; Figure 2B). Overall, mortality was considerably lower than the recruitment seen during May. Relative to the values of recruit density recorded on 24 June (peak recruit density before any mortality had occurred), the average percent mortality rate on 26 October was $10.5 \%(N=$ 4 quadrats).

\section{Recruit Density}

During the studied period, the density of live recruits varied significantly over time (repeated-measures ANOVA, $F=7.70$, $P<0.001$; Figure 2C). One of the four clearings could not be surveyed on 10 and 17 May because of intense wave 



FIGURE 1 | (A) Map showing the position of Western Head and other intertidal locations from the Nova Scotia coast mentioned in the text. (B) View of the coast of Western Head during a low tide. (C) Photographs of one of the clearings taken at low tide on eight representative sampling dates (see section Materials and Methods for the full list of sampling dates). Each photograph shows the inner frame $(10 \mathrm{~cm} \times 10 \mathrm{~cm})$ of the PVC quadrat that was used as a size reference to measure the body size of each barnacle recruit. The arrow in the photograph for the last sampling date points to a dead barnacle (empty shell). These photographs were taken by R. A. Scrosati.

action. As that clearing had a lower recruit density than the others, the mean recruit density reported for those two dates is higher than the means expected from the dotted line shown in Figure 2C joining the means for 9 and 23 May, which were calculated (like for all other dates) using density data for all four clearings. Overall, recruit density increased strongly during May and weakly during June and decreased weakly due to mortality between late July and October. On average for the four surveyed clearings, peak recruit density (recorded on 24 June at the end of the recruitment season) was 58.5 recruits $\mathrm{dm}^{-2}$.

\section{Recruit Size}

The temporal change in recruit size is shown in Figure 2D. This figure summarizes the data for the recruits found on 9 May because those are the earliest (and most numerous) group of recruits that appeared on the shore. This approach allows us to evaluate growth during the entire study period 
A

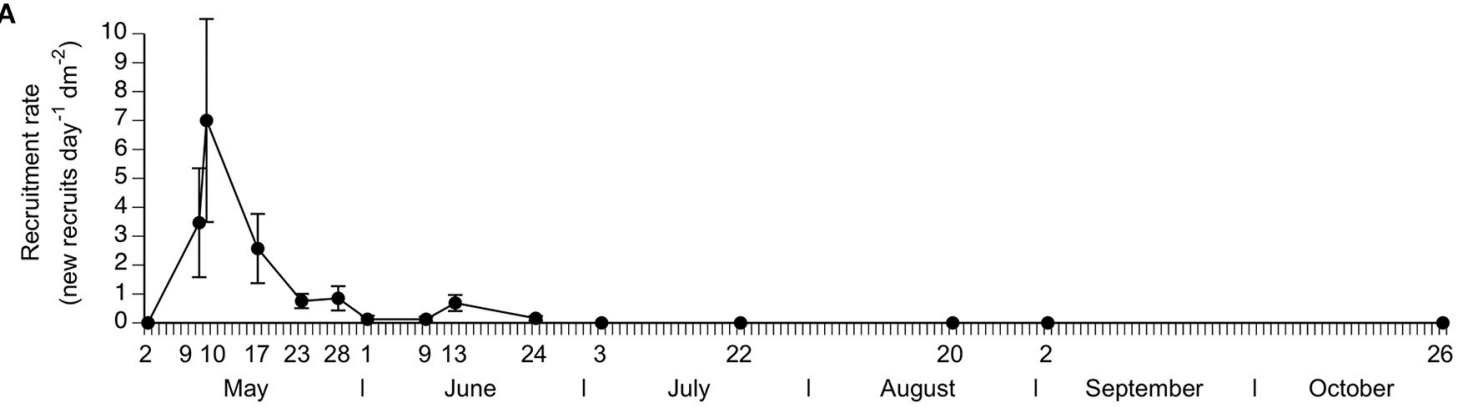

B



C

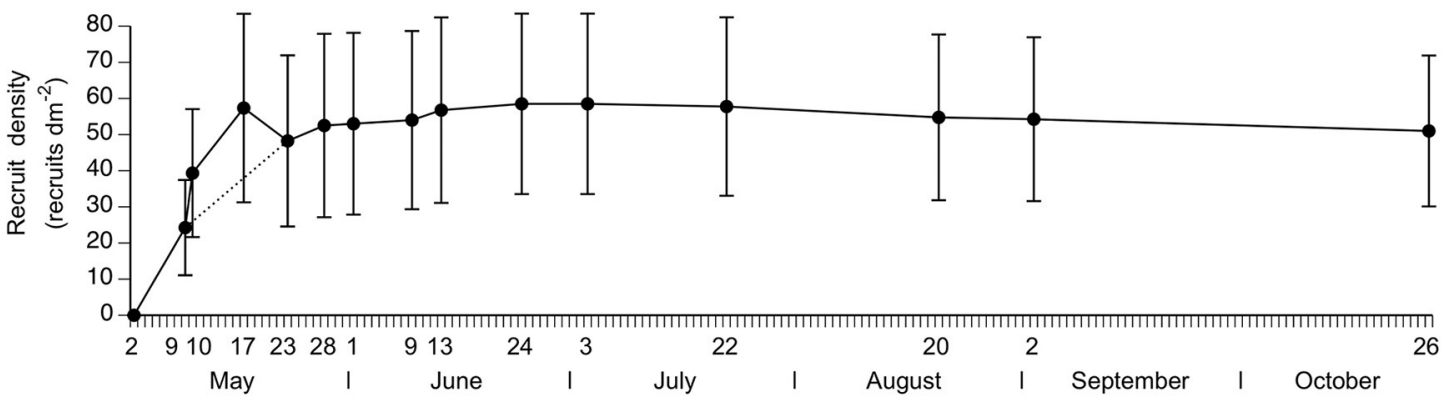

D

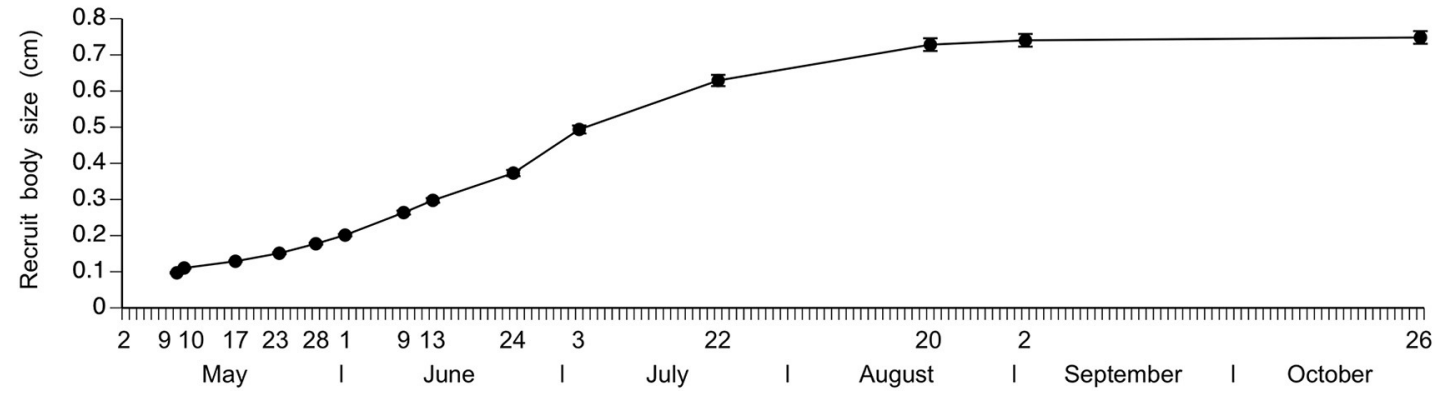

FIGURE 2 | Temporal change (mean \pm SE) in (A) barnacle recruitment rate (number of recruits appeared on the substrate since the previous sampling date expressed per day and per unit area), (B) mortality rate of recruits (number of dead recruits appeared on the substrate since the previous sampling date expressed per day and per unit area), (C) recruit density (number of live recruits per unit area), and (D) barnacle body size (basal shell diameter of live recruits).

using the same organisms. During the studied period, recruit size varied significantly over time (repeated-measures ANOVA, $F=1,028.95, P<0.001)$. For size calculations, we did not measure the size of the empty barnacle shells found between 22 July and 26 October because they indicated dead barnacles. Overall, recruit size followed a sigmoidal pattern throughout the study period, growth increasing from May to July and decreasing from July to October. The largest barnacle recorded at the end of the study period on 26 October was $1.1 \mathrm{~cm}$ in basal shell diameter. A visual example of the temporal changes in recruit size is offered in Figure 1C. 


\section{DISCUSSION OF THE SALIENT PATTERNS}

The short recruitment season of Semibalanus balanoides compared with other barnacle species whose recruitment spans several months (e.g., on the NE Pacific coast; Navarrete et al., 2008) suggests that monthly variation in the drivers of recruitment may be particularly critical for $S$. balanoides. For example, unusually extreme events (e.g., food shortages, heat waves) in May might result in recruitment failures or diminished recruitment affecting population persistence. Such monthly events would not equally affect barnacle species for which strong recruitment in other months could have a compensatory influence. On the other hand, the appearance of most $S$. balanoides recruits in the first few weeks of the recruitment season at Western Head parallels the general trend found for S. balanoides in Europe, even though differences among sites naturally occur (Jenkins et al., 2000).

The timing of recruitment of Semibalanus balanoides changes latitudinally along the Atlantic coast of North America. Past studies in Nova Scotia yielded similar results. For example, a study done in 1988 at Sandy Cove $(103 \mathrm{~km}$ northeast of Western Head) found that settlement started on 22 April and that the main settlement period ended on 15 June at middle and low elevations (Minchinton and Scheibling, 1993). A study done in 2011 at Glasgow Head $(328 \mathrm{~km}$ northeast of Western Head) in semi-exposed habitats found that recruitment started after 2 May and that no settlement occurred after 15 June at the high intertidal zone (Ellrich et al., 2016a). Studies done at Deming Island ( $308 \mathrm{~km}$ northeast of Western Head) in semi-exposed habitats found that recruitment started on 30 April in 2012 and on 9 May in 2013 on areas located predominantly at the midintertidal zone (Ellrich et al., 2016b). It is thus possible that, in Nova Scotia, recruitment may start a few days earlier at middle elevations than at high elevations. Field observations done by R. Scrosati at various wave-exposed locations spanning $415 \mathrm{~km}$ of the Atlantic coast of Nova Scotia between 2014 and 2021 never found any settled cyprids or recruits before early May at high-to-middle elevations (the zone surveyed for this study). Therefore, the recruitment season in these environments spans May and June. Toward lower latitudes along the Atlantic coast of North America, recruitment occurs increasingly earlier in the year. For example, in southern New Brunswick (situated between Nova Scotia and New England, USA), settlement begins in April and ends in May (Bousfield, 1954; Le Tourneux and Bourget, 1988). In New England itself, recruitment takes place between January or February and April or May (Hutchins, 1947; Bertness et al., 1992; Jarrett and Pechenik, 1997; Pineda et al., 2002, 2006; Blythe and Pineda, 2009) and settlement ceases in late May in Maine, to the north, but in late March in Rhode Island, to the south (Bertness and Gaines, 1993). A similar latitudinal gradient in the timing of $S$. balanoides recruitment occurs in Europe, as recruitment occurs in summer on the Barents Sea coast in northern Russia (Hutchins, 1947) but in mid- to late winter in the United Kingdom and NW Spain, near its southern distribution limit (Hutchins, 1947; Lewis, 1986).

The mortality of recruits observed between July and September at Western Head was likely caused by heat and desiccation stress during low tides (Bertness and Gaines, 1993; Menge, 2000). For instance, temperature measured at low tide on the rocky substrate near the surveyed clearings at Western Head exceeded $30^{\circ} \mathrm{C}$ on 8 days in July-August 2019 (with a maximum value of $35^{\circ} \mathrm{C}$ ), while sea surface temperature (SST) measured at high tide barely surpassed $17^{\circ} \mathrm{C}$ during that period. In June, temperature at low tide only surpassed $28^{\circ} \mathrm{C}$ in 2 days and was lower than $25^{\circ} \mathrm{C}$ in 22 days (Scrosati et al., 2020). At the surveyed high-to-middle elevations in these wave-exposed habitats, barnacle predators (dogwhelks, Nucella lapillus) were rare during the studied period. Dogwhelks are more common at lower elevations on more sheltered habitats (Minchinton and Scheibling, 1993; Menge, 2000).

The ultimate drivers of recruit density at the end of the recruitment season at Western Head remain to be determined, although larval and food supply (Menge and Menge, 2019; Shanks and Morgan, 2019) together with benign conditions before the summer and scarcity of predators must play a predominant role. At lower elevations in wave-exposed habitats at Western Head, recruitment is higher, likely because of increased larval supply due to the longer submergence periods (Scrosati, 2020); a similar pattern was found in Rhode Island (Bertness et al., 1992). At other wave-exposed locations surveyed at high-to-middle elevations on the Nova Scotia coast, recruit density can be higher (up to a locationwise average of 212 recruits $\mathrm{dm}^{-2}$ ) and positively related to planktonic food supply and SST (Scrosati and Ellrich, 2018). On other shores, Semibalanus balanoides can exhibit even higher recruitment. For example, recruit density in wave-exposed locations can range between $800-1,100$ recruits $\mathrm{dm}^{-2}$ in Maine (Menge, 1978) and 1,6002,000 recruits $\mathrm{dm}^{-2}$ in Ireland (Jenkins et al., 2000). Thus, waveexposed intertidal environments on the open Atlantic coast of Nova Scotia show relatively moderate values.

The recruits of Semibalanus balanoides showed a classic sigmoidal growth pattern (Sköld et al., 2001; Tjørve and Tjørve, 2017) until reaching adult sizes in the fall. Organisms of a similar age collected in 2011 at Glasgow Head, north of Western Head on the Nova Scotia coast, had reached reproductive maturity because they had eggs (Ellrich et al., 2016a). Thus, the grown recruits seen in October at Western Head may have been reproductive as well. This assumption is further supported by the notion that S. balanoides individuals with basal widths $<4 \mathrm{~mm}$ are typically non-reproductive (Pineda et al., 2002; Bouchard and Aiken, 2012). We also note that, at Western Head, S. balanoides recruits generally grow larger than at other wave-exposed sites surveyed at the same elevation zone along the Atlantic coast of Nova Scotia. This growth is positively related to nearshore phytoplankton abundance (Scrosati and Ellrich, 2019), which could be driven in part by coastal upwelling, a phenomenon that is prevalent in summer at Western Head (Scrosati and Ellrich, 2020a,b). Body size and coastal phytoplankton abundance are also related in $S$. balanoides from Europe (Burrows et al., 2010).

Finally, the relative importance of recruitment vs. postrecruitment processes for population maintenance has received considerable attention in intertidal ecology, with results that often depend on the environmental context (Scrosati, 1998; Menge, 2000; Svensson et al., 2004). The data hereby described 
for Western Head and the positive recruit-adult relationship found for similar habitats along the Nova Scotia coast (Scrosati and Ellrich, 2018) suggest that recruitment plays an important role in structuring barnacle populations in mid-tohigh intertidal, wave-exposed environments on this coast.

\section{MAIN CONCLUSIONS}

- Recruitment of Semibalanus balanoides in wave-exposed rocky intertidal habitats at Western Head occurred in May and June, which is thus confirmed to be the recruitment season.

- Nearly 3/4 of the recruits appeared during the first half of May, while 9 in 10 recruits were on the substrate by the end of May, so recruitment during June was low, with no recruits appearing near the end of that month.

- No recruit mortality occurred during the recruitment season or in early July.

- Recruit mortality only occurred between late July and the end of the study (late October), although with rates considerably lower than May recruitment rates.

- Recruits grew in size following a sigmoidal pattern until reaching adult sizes in the fall.

- Overall, these findings indicate that recruit density measured between late June and early July would accurately represent the rate of annual recruitment for $S$. balanoides.

\section{REFERENCES}

Belt, K. M., Cole, S. W., and Scrosati, R. A. (2009). Intertidal barnacles as indicators of the intensity of scour by sea ice. Mar. Ecol. Prog. Ser. 381, 183-187. doi: $10.3354 /$ meps07935

Bertness, M. D., and Gaines, S. D. (1993). Larval dispersal and local adaptation in acorn barnacles. Evolution 47, 316-320. doi: 10.1111/j.1558-5646.1993.tb01221.x

Bertness, M. D., Gaines, S. D., Bermudez, D., and Sanford, E. (1991). Extreme spatial variation in the growth and reproductive output of the acorn barnacle Semibalanus balanoides. Mar. Ecol. Prog. Ser. 75, 91-100. doi: 10.3354/meps075091

Bertness, M. D., Gaines, S. D., Stephens, E. G., and Yund, P. O. (1992). Components of recruitment in populations of the acorn barnacle Semibalanus balanoides (Linnaeus). J. Exp. Mar. Biol. Ecol. 156, 199-215. doi: 10.1016/0022-0981(92)90246-7

Bertness, M. D., Leonard, G. H., Levine, J. M., and Bruno, J. F. (1999). Climate-driven interactions among rocky intertidal organisms caught between a rock and a hot place. Oecologia 120, 446-450. doi: 10.1007/s0044200 50877

Blythe, J. N., and Pineda, J. (2009). Habitat selection at settlement endures in recruitment time series. Mar. Ecol. Prog. Ser. 396, 77-84. doi: 10.3354/meps08309

Bouchard, G. M., and Aiken, R. B. (2012). Latitudinal variation in the reproductive cycle and size of the northern rock barnacle Semibalanus balanoides (L.) (Cirripedia, Archaeobalanidae) in the Bay of Fundy. Crustaceana 85, 779-787. doi: $10.1163 / 156854012 X 650214$

Bousfield, E. L. (1954). The distribution and spawning seasons of barnacles on the Atlantic coast of Canada. Bull. Natl. Mus. Canada 132, 112-154.

Burrows, M. T., Jenkins, S. R., Robb, L., and Harvey, R. (2010). Spatial variation in size and density of adult and post-settlement Semibalanus balanoides: effects of oceanographic and local conditions. Mar. Ecol. Prog. Ser. 398, 207-219. doi: $10.3354 / \mathrm{meps} 08340$

\section{DATA AVAILABILITY STATEMENT}

The full data set described in this Data Report is freely available from the figshare online repository: https://doi.org/10.6084/m9. figshare.16847206.v1.

\section{AUTHOR CONTRIBUTIONS}

RS designed the study, conducted the field surveys, and wrote the manuscript. JH and RS analyzed the photographs. Both authors approved the final manuscript version.

\section{FUNDING}

This study was funded by a Discovery Grant awarded to RS by the Natural Sciences and Engineering Research Council of Canada (NSERC, grant number 311624).

\section{ACKNOWLEDGMENTS}

We are grateful to two reviewers and the Associate Editor for constructive comments that helped us to improve the manuscript.

Connell, J. H. (1961). Effects of competition, predation by Thais lapillus, and other factors on natural populations of the barnacle Balanus balanoides. Ecol. Monogr. 31, 61-104. doi: 10.2307/1950746

Crickenberger, S., and Wethey, D. S. (2018). Annual temperature variation as a time machine to understand the effects of long-term climate change on a poleward range shift. Glob. Change Biol. 24, 3804-3819. doi: 10.1111/gcb.14300

Crisp, D. J. (1964). Racial differences between North American and European forms of Balanus balanoides. J. Mar. Biol. Assoc. U K. 44, 33-45. doi: 10.1017/S0025315400024644

Ellrich, J. A., Scrosati, R. A., Bertolini, C., and Molis, M. (2016a). A predator has nonconsumptive effects on different life-history stages of a prey. Mar. Biol. 163:5. doi: 10.1007/s00227-015-2778-6

Ellrich, J. A., Scrosati, R. A., Romoth, K., and Molis, M. (2016b). Adult prey neutralizes predator nonconsumptive limitation of prey recruitment. PLoS ONE 11:e0154572. doi: 10.1371/journal.pone.0154572

Flight, P. A., O’Brien, M. A., Schmidt, P. S., and Rand, D. M. (2012). Genetic structure and the North American postglacial expansion of the barnacle, Semibalanus balanoides. J. Hered. 103, 153-165. doi: 10.1093/jhered/esr083

Harley, C. D. G. (2008). Tidal dynamics, topographic orientation, and temperature-mediated mass mortalities on rocky shores. Mar. Ecol. Prog. Ser. 371, 37-46. doi: 10.3354/meps07711

Helmuth, B., Broitman, B. R., Blanchette, C. A., Gilman, S., Halpin, P., Harley, C. D. G., et al. (2006). Mosaic patterns of thermal stress in the rocky intertidal zone: implications for climate change. Ecol. Monogr. 76, 461-479. doi: 10.1890/ 0012-9615(2006)076[0461:MPOTSI]2.0.CO;2

Hunt, H. L., and Scheibling, R. E. (2001). Patch dynamics of mussels on rocky shores: integrating process to understand pattern. Ecology 82, 3213-3231. doi: 10.1890/0012-9658(2001)082[3213:PDOMOR]2.0.CO;2

Hutchins, L. W. (1947). The bases for temperature zonation in geographical distribution. Ecol. Monogr. 17, 325-335. doi: 10.2307/1948663

Jarrett, J. N., and Pechenik, J. A. (1997). Temporal variation in cyprid quality and juvenile growth capacity for an intertidal barnacle. Ecology 78, 1262-1265. doi: 10.1890/0012-9658(1997)078[1262:TVICQA]2.0.CO;2 
Jenkins, S. R., Åberg, P., Cervin, G., Coleman, R. A., Delany, J., Della Santina, P., et al. (2000). Spatial and temporal variation in settlement and recruitment of the intertidal barnacle Semibalanus balanoides (L.) (Crustacea: Cirripedia) over a European scale. J. Exp. Mar. Biol. Ecol. 243, 209-225. doi: 10.1016/S0022-0981(99)00121-5

Le Tourneux, F., and Bourget, E. (1988). Importance of physical and biological settlement cues used at different spatial scales by the larvae of Semibalanus balanoides. Mar. Biol. 97, 57-66. doi: 10.1007/BF00391245

Lewis, J. R. (1986). Latitudinal trends in reproduction, recruitment, and population characteristics of some rocky littoral molluscs and cirripedes. Hydrobiologia 142, 1-13. doi: 10.1007/BF00026742

Menge, B. A. (1978). Predation intensity in a rocky intertidal community. Effect of an algal canopy, wave action, and desiccation on predator feeding rates. Oecologia 34, 17-35. doi: 10.1007/BF00346238

Menge, B. A. (2000). Recruitment vs. postrecruitment processes as determinants of barnacle population abundance. Ecol. Monogr. 70, 265-288. doi: 10.1890/00129615(2000)070[0265:RVPPAD $2.0 . C O ; 2$

Menge, B. A., and Menge, D. N. L. (2019). Testing the intermittent upwelling hypothesis: comment. Ecology 100:e02476. doi: 10.1002/ecy.2476

Menge, B. A., and Sutherland, J. P. (1976). Species diversity gradients: synthesis of the roles of predation, competition, and temporal heterogeneity. Am. Nat. 110, 351-369. doi: 10.1086/283073

Minchinton, T. E., and Scheibling, R. E. (1993). Variations in sampling procedure and frequency affect estimates of recruitment of barnacles. Mar. Ecol. Prog. Ser. 99, 83-88. doi: 10.3354/meps099083

Mislan, K. A. S., Blanchette, C. A., Broitman, B. R., and Washburn, L. (2011). Spatial variability of emergence, splash, surge, and submergence in wave-exposed rocky-shore ecosystems. Limnol. Oceanogr. 56, 857-866. doi: 10.4319/lo.2011.56.3.0857

Navarrete, S. A., Broitman, B. R., and Menge, B. A. (2008). Interhemispheric comparion of recruitment to intertidal communities: pattern persistence and scales of variation. Ecology 89, 1308-1322. doi: 10.1890/07-0728.1

Pineda, J., Riebensahm, D., and Medeiros-Bergen, D. (2002). Semibalanus balanoides in winter and spring: larval concentration, settlement, and substrate occupancy. Mar. Biol. 140, 789-800. doi: 10.1007/s00227-001-0751-z

Pineda, J., Starczak, V., and Stueckle, T. A. (2006). Timing of successful settlement: demonstration of a recruitment window in the barnacle Semibalanus balanoides. Mar. Ecol. Prog. Ser. 320, 233-237. doi: 10.3354/meps320233

Scrosati, R. (1998). Mechanisms of recolonization of the clonal intertidal alga Mazzaella cornucopiae (Rhodophyta, Gigartinaceae) after disturbances. Can. J. Bot. 76, 1717-1724. doi: 10.1139/b98-124

Scrosati, R. A. (2020). Effects of intertidal elevation on barnacle recruit density and size in wave-exposed habitats on the Atlantic Canadian coast. Northeast. Nat. 27, 186-194. doi: 10.1656/045.027.0201

Scrosati, R. A. (2021). Nonconsumptive predator effects on prey demography: recent advances using intertidal invertebrates. Front. Ecol. Evol. 9:626869. doi: $10.3389 /$ fevo.2021.626869

Scrosati, R. A., and Ellrich, J. A. (2019). A 5-year study (2014-2018) of the relationship between coastal phytoplankton abundance and intertidal barnacle size along the Atlantic Canadian coast. PeerJ 7:e6892. doi: 10.7717/peerj.6892

Scrosati, R. A., and Ellrich, J. A. (2020a). Latitudinal and seasonal changes in intertidal sea surface temperature along the Atlantic coast of Nova Scotia, Canada. Front. Mar. Sci. 7:592. doi: 10.3389/fmars.2020.00592

Scrosati, R. A., and Ellrich, J. A. (2020b). Marked contrast in winddriven upwelling on the southeastern Nova Scotia coast in July of two years differing in ENSO conditions. Oceanol. Hydrobiol. Stud. 49, 81-87. doi: 10.1515/ohs-2020-0008
Scrosati, R. A., Ellrich, J. A., and Freeman, M. J. (2020). Half-hourly changes in intertidal temperature at nine wave-exposed locations along the Atlantic Canadian coast: a 5.5-year study. Earth Syst. Sci. Data 12, 2695-2703. doi: 10.5194/essd-12-2695-2020

Scrosati, R. A., and Ellrich,. J. A. (2018). Benthic-pelagic coupling and bottomup forcing in rocky intertidal communities along the Atlantic Canadian coast. Ecosphere 9:e02229. doi: 10.1002/ecs2.2229

Scrosati, R. A., and Freeman, M. J. (2019). Density of intertidal barnacles along their full elevational range of distribution conforms to the abundant-centre hypothesis. PeerJ 7:e6719. doi: 10.7717/peerj.6719

Scrosati, R. A., and Holt, J. K. (2021). Size of Barnacle Recruits During and After the 2019 Recruitment Season at Western Head, Nova Scotia, Canada. Figshare Dataset. Available online at: https://doi.org/10.6084/m9.figshare.16847206.v1 (accessed October 21, 2021).

Sejr, M. K., Mouritsen, K. N., Krause-Jensen, D., Olesen, B., Blicher, M. E., and Thyrring, J. (2021). Small-scale factors modify impacts of temperature, ice scour, and waves and drive rocky intertidal community structure in a Greenland fjord. Front. Mar. Sci. 7:607135. doi: 10.3389/fmars.2020. 607135

Shanks, A. L., and Morgan, S. G. (2019). Testing the intermittent upwelling hypothesis: reply. Ecology 100:e02516. doi: 10.1002/ecy.2516

Shanks, A. L., Morgan, S. G., MacMahan, J., Reniers, A. J. H. M., Jarvis, M., Brown, J., et al. (2014). Onshore transport of plankton by internal tides and upwelling-relaxation events. Mar. Ecol. Prog. Ser. 502, 39-51. doi: 10.3354/meps 10717

Sköld, M., Josefson, A. B., and Loo, L. O. (2001). Sigmoidal growth in the brittle star Amphiura filiformis (Echinodermata: Ophiuroidea). Mar. Biol. 139, 519-526. doi: $10.1007 / \mathrm{s} 002270100600$

Svensson, C. J., Jenkins, S. R., Hawkins, S. J., Myers, A. A., Range, P., Paula, J., et al. (2004). Models of open populations with space-limited recruitment in stochastic environments: relative importance of recruitment and survival in populations of Semibalanus balanoides. Mar. Ecol. Prog. Ser. 275, 185-197. doi: $10.3354 /$ meps 275185

Tide and Current Predictor (2021). Liverpool Bay, Nova Scotia. Available online at: http://tide.arthroinfo.org/tideshow.cgi?site=Liverpool+Bay\%2C+Nova+Scotia (accessed November 15, 2021).

Tjørve, K. M. C., and Tjørve, E. (2017). A proposed family of Unified models for sigmoidal growth. Ecol. Modell. 359, 117-127. doi: 10.1016/j.ecolmodel.2017.05.008

Conflict of Interest: The authors declare that the research was conducted in the absence of any commercial or financial relationships that could be construed as a potential conflict of interest.

Publisher's Note: All claims expressed in this article are solely those of the authors and do not necessarily represent those of their affiliated organizations, or those of the publisher, the editors and the reviewers. Any product that may be evaluated in this article, or claim that may be made by its manufacturer, is not guaranteed or endorsed by the publisher.

Copyright (๑) 2021 Scrosati and Holt. This is an open-access article distributed under the terms of the Creative Commons Attribution License (CC BY). The use, distribution or reproduction in other forums is permitted, provided the original author(s) and the copyright owner(s) are credited and that the original publication in this journal is cited, in accordance with accepted academic practice. No use, distribution or reproduction is permitted which does not comply with these terms. 